\title{
PERSPECTIVAS DA PÓS-GRADUAÇÃO EM GEOGRAFIA NO BRASIL: CONSIDERAÇÕES A PARTIR DAS EDIÇÕES DO ENANPEGE (1995/2013)
}

\author{
Perspectives of the post-graduate geography in Brazil: considerations from \\ ENANPEGE editions (1995/2013) \\ Vanessa Teixeira \\ Mestra em Geografia pela Universidade Estadual do Centro-Oeste (UNICENTRO) \\ vanessateixeira1904@hotmail.com
}

Artigo enviado para publicação em 06/08/2018 e aceito em 24/05/2019

DOI: $10.12957 /$ tamoios.2019.36578

\begin{abstract}
Resumo
Esta nota de pesquisa trata sobre as análises realizadas na construção da dissertação de Mestrado, vinculada ao Programa de Pós-Graduação em Geografia, pela Universidade Estadual do Centro-Oeste do Paraná, a qual tem por objetivo destacar as características do principal evento da pós-graduação em Geografia no Brasil, considerado por pesquisadores como espaço privilegiado de debates da área e suas subáreas no nível da pós-graduação - o Encontro Nacional da Associação Nacional de Pesquisa e PósGraduação (ENANPEGE). Utilizando-se de entrevistas com ex-presidentes da ANPEGE, anais do ENANPEGE, seus relatórios e atas procurou-se trazer questões e itens constantes nos encontros. É nessa mesma perspectiva, que a escolha temporal do estudo se coloca, assim, na tentativa de visualizar o percurso do encontro enquanto elemento do desenvolvimento do conhecimento da pós-graduação em Geografia brasileiro desde o primeiro encontro.
\end{abstract}

Palavras-chaves: ENANPEGE, Produção científica, Geografia.

\begin{abstract}
This research note deals with the analyzes carried out in the construction of the Master's thesis, linked to the Graduate Geography Program, State University of Central West of Parana, which aims to highlight the features of the main event of the post- degree in Geography in Brazil, considered by researchers as a privileged space of the area debates and its sub-areas in the graduate level - the National Meeting of the National Association for Research and graduate Studies (ENANPEGE). Using interviews with former presidents of ANPEGE, ENANPEGE the proceedings, their reports and minutes we tried to bring issues and the items in the meetings. It is in this same perspective, the temporal choice of study places, so in an attempt to display the route of the meeting as part of the development of knowledge graduate in Brazilian Geography from the first meeting.
\end{abstract}

Keywords: ENANPEGE, scientific production, Geography. 


\section{Introdução}

A presente texto ${ }^{1}$, como uma nota de pesquisa, tem por objetivo destacar as características do principal evento da pós-graduação em Geografia no Brasil, o Encontro Nacional da Associação Nacional de Pesquisa e Pós-graduação em Geografia (ENANPEGE), considerado por pesquisadores como espaço privilegiado de debates da área e suas subáreas no nível da pós-graduação, que agrega, em cada um de seus encontros, além de novos Grupos de Trabalhos (GTs), questões importantes nas mudanças que estão em curso: informações, resultados, possibilidades e inserções de novos conhecimentos teóricos com enfoque geográfico que se somem a produção científica e a abordagem política da ANPEGE.

O ENANPEGE é promovido pela Associação Nacional de Pesquisa e Pósgraduação em Geografia - ANPEGE. Todavia, é uma associação que tem uma trajetória e, portanto, uma história (Entrevista José Borzachiello da Silva, 2015), congregando a pós-graduação e a pesquisa no Brasil, orientando o crescimento e a qualidade dos programas de pós-graduação, bem como nas suas ações, visando o fortalecimento teórico da ciência geográfica. As atribuições da ANPEGE são amplas para uma diretoria composta por três membros (Presidente; Secretário e Tesoureiro): são atividades e problemas sobre a gestão; administração; pensar em política enquanto que a representante; as políticas de pesquisa; a produção científica; atentar ao que esta acontecendo na CAPES; na articulação com o representante; com outros órgãos públicos e de fomento; pesquisas que se encontram sendo realizadas na pós-graduação no país; etc. Além disso, Geralda de Almeida (2011, p. 174) destaca a ANPEGE como uma entidade um pouco diferente da $\mathrm{AGB}$, isto é, "entidade que não mais tem o ímpeto do trabalho do geógrafo militante politicamente porque já espera que ele venha com essa militância praticada em outras instâncias".

$\mathrm{Na}$ realidade, deve-se lembrar de que a entidade é uma produção histórica, que apresenta uma sucessão de tempos os quais lhe conferem especificidades e novos fatos, desafios e preocupações, bem como congrega um número maior de participantes de programas de pós-graduação associados e não sócios. Neste sentido, vem tentando atender as novas necessidades da estrutura de pesquisa e, ao mesmo tempo em que as suas "conquistas" foram sendo consolidadas, seu modelo organizacional e estrutural permaneceu quase o mesmo (década de 1990 quando foi criada) diante dessas novas demandas e modelos. 


\section{Edições do ENANPEGE (1995-2013)}

Em meio às transformações mundiais e, consequentemente, no conhecimento científico, novas demandas são impostas diariamente as formas de estudo e disseminação de trabalhos acadêmicos. Neste processo, a Geografia consolida-se em relação a sua tradição na realização de eventos com grande representatividade no cenário científico nacional e internacional. Em relação a pós-graduação, este fato se acentua representado pelo ENANPEGE, que possui periodicidade de realização de dois anos.

O ENANPEGE foi realizado em sua $11^{a}$ edição em 2015, acompanhado por temáticas vinculadas ao cenário científico contemporâneo, diálogos e atividades que possibilitam discutir, trocar experiências e avaliar questões e ações significativas do pensamento geográfico. O mesmo é estruturado em conferências, Grupos de Trabalho (GT), Mesas-redondas e Fóruns (pesquisadores, coordenadores, estudantes e editores). Assim, as conferências, as mesas-redondas e os GTs constituem oportunidades para o aprofundamento dos debates e na troca de saberes que propiciam o avanço da ciência geográfica e a consolidação da pós-graduação em Geografia no Brasil (BOLETIM INFORMATIVO DA ANPEGE, 2009).

As conferências fundamentam-se na temática geral do evento, com um aprofundamento teórico e pesquisas que alicerçam o fazer geográfico (BOLETIM INFORMATIVO DA ANPEGE, 2009). Já as mesas-redondas são momentos de aprofundamento de debates em temáticas de interesses da pós-graduação em Geografia no país, com seus temas vinculados a temática geral do evento, assim, é um detalhamento da discussão principal que contempla a edição do encontro. Em relação aos GTs, estruturados em eixos temáticos, são espaços de divulgação e ilustração (em formato de pôster ou oral) de diferentes estudos da realidade nacional e internacional.

O mapa 1 apresenta a distribuição, por estados da federação, dos eventos ENANPEGE e suas respectivas cidades-sede. 


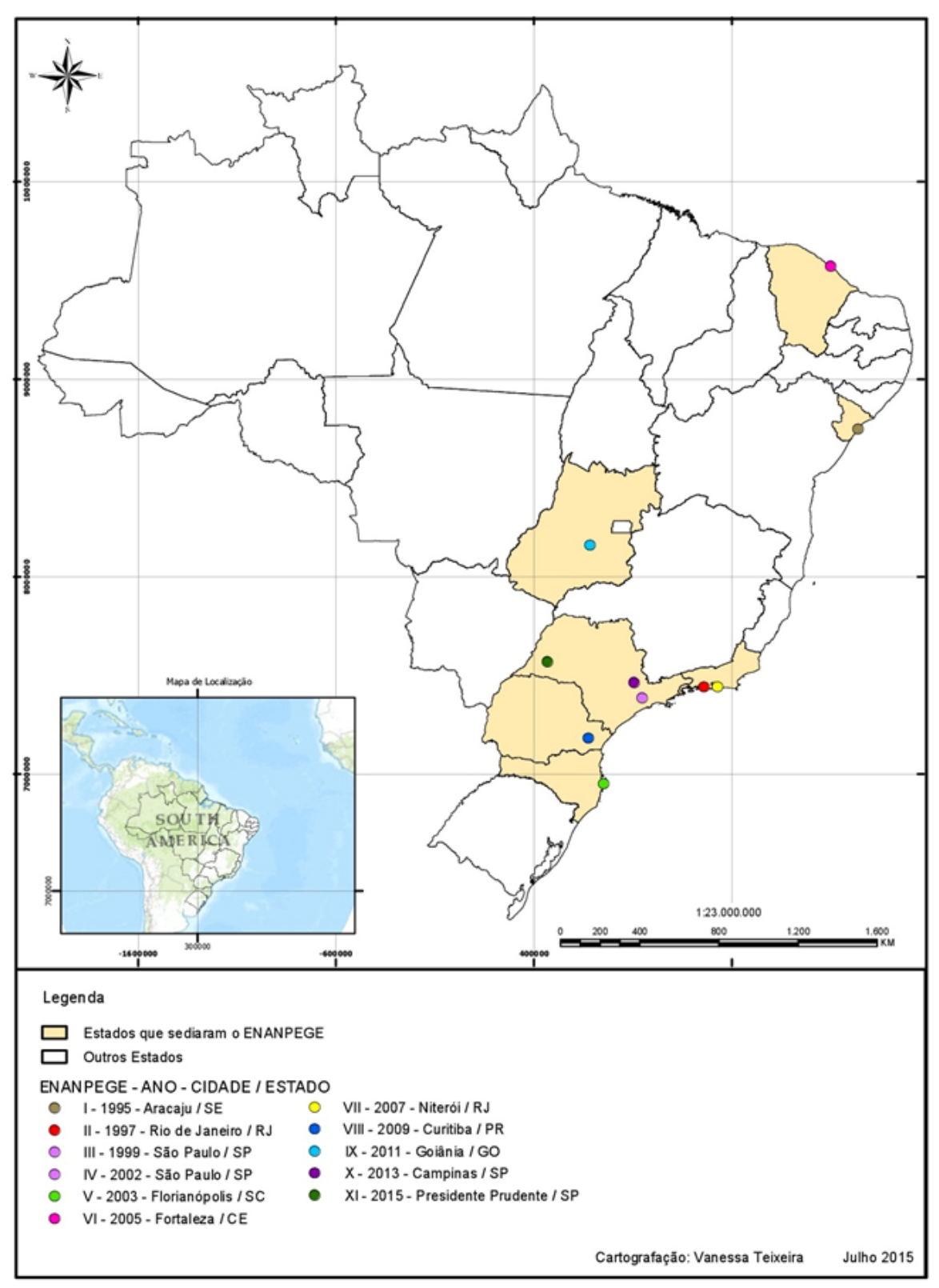

Mapa 1: Brasil - Distribuição das sedes dos eventos ENANPEGE (1995/2015).

Pode-se verificar, no mapa 1, os pontos coloridos que demarcam a localização de cada edição do ENANPEGE (1995-2015), com nítida concentração para alguns estados da federação brasileira, significativamente no Sudeste do país, que sediou 6 edições, dos 11 encontros do ENANPEGE realizados, ou seja, mais de 50\%. Destes, quatro ocorreram no estado de São Paulo (o município de São Paulo sediou o encontro por duas vezes) e duas no estado do Rio de Janeiro. Na sequência, em número de edições, estão as regiões Nordeste e Sul, ambas com duas, e a região Centro-Oeste, com uma edição em Goiás.

Em relação ao número de participantes, por edição do ENANPEGE, os dados do período de 1995 a $2013^{2}$ estão expostos no gráfico 1. 
Gráfico 1: Número de inscritos por ano de realização do ENANPEGE (1995/2013)*.

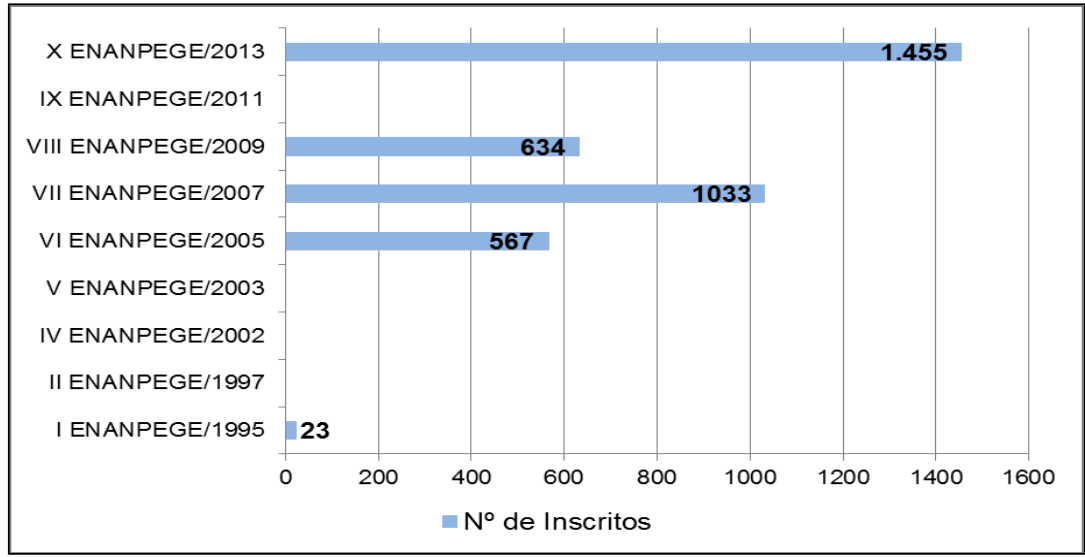

Fonte: Site ANPEGE- Histórico.

Org.: TEIXEIRA, V. (2016).

*No ano de1999 não ocorreu o encontro do ENANPEGE.

De acordo com o gráfico 1, em 1995 (I ENANPEGE) o encontro reuniu 23 participantes, no ano de 2005 (VI ENANPEGE) o encontro apresentou 567 participações, em 2007 (VII ENANPEGE) um total de 1.033 participações e, em 2009 (VIII ENANPEGE), esse número de participantes caiu para 634 participações. Em 2013, no X ENANPEGE, verifica-se um total de 1.455 participações.

A explicação para esse fato é a maior concentração espacial de programas de pósgraduação em Geografia nos últimos anos, com uma significativa ampliação do número de cursos de mestrado e doutorado. Desta forma, verifica-se um acréscimo ao ingresso de discentes nos programas e uma intensificação na participação do ENANPEGE para disseminação de suas pesquisas.

Mesmo com o reconhecimento e a expansão que adquiriu em número de participantes, em cada um de seus eventos, a ANPEGE mantém e preserva algumas de suas características originais dos primeiros encontros. Nesse contexto, vemos como um dos elementos que justifica o grande reconhecimento do evento, a preocupação em que os trabalhos submetidos sejam avaliados por um conjunto de atributos que demandam rigor avaliativo e que o faz manter a qualidade nas pesquisas disseminadas.

O ENANPEGE é uma reunião ampla de trabalhos que oferecem uma visão do conjunto da produção em Geografia de diferentes programas de pós-graduação do Brasil, compartilhando as diferentes temáticas de interesse nas pesquisas em curso, bem como nas suas abordagens teórico-metodológicas, trazendo um panorama dos diferentes contextos e escalas de pesquisas.

Para Francisco de Assis Mendonça (em entrevista): 
[...] é um evento que fortalece a entidade [ANPEGE] capilarizando seus papeis e envolvendo as pessoas, o que leva a alcançar o máximo dos objetivos da entidade que é a promoção do avanço do conhecimento da Geografia através do debate, das exposições dos trabalhos. (Entrevista Francisco de Assis Mendonça, 2016).

O I ENANPEGE ${ }^{3}$ foi realizado em Aracaju - SE, em 1995, com a temática "Território brasileiro e Globalização". O encontro "foi organizado pela secretaria executiva, sob sua inteira responsabilidade, outorgada pelo Presidente que estava em viagem de estudos no exterior (França)" (Entrevista Maria Adélia Aparecida de Souza, 2015).

Sobre a escolha da temática geral, Maria Adélia Aparecida de Souza (em entrevista) explica que julgou pertinente, naquela situação, colocar os geógrafos brasileiros diante da temática da globalização que se vigorava, analisando o Brasil diante desse processo.

Nesse sentido, Maria Adélia Aparecida de Souza (em entrevista) menciona que se tratava de um tema debatido pelas sociedades científicas da área de humanas como um “discurso político que se forjava intensamente em todas as instâncias políticas e os geógrafos não poderiam continuar com seu empirismo exacerbado, pesquisando minucias decorrentes das visões tradicionais pesquisadas pela nossa disciplina". Assim, complementa que naquela situação procuraram "mudar um pouco a miudeza geográfica e empirista que caracteriza nossa disciplina até hoje, não dando absolutamente conta das mudanças metodológicas, políticas e técnicas que gritam pelo mundo todo" (Entrevista Maria Adélia Aparecida de Souza, 2015).

De acordo com Mendonça (em entrevista), o primeiro evento foi uma grande reunião que tinha que atrair, se mostrar e agregar, com mesas redondas consistentes, grandes conferências, apresentação de trabalhos modestos, coleguismo e amizade. Foi um evento aberto, isto é, não era somente para pessoas pós-graduadas ou pós-graduandos, uma vez que na década de 1990, no Brasil, havia muitos cursos de especialização em Geografia ou correlatos e poucos cursos de pós-graduação.

Neste evento foram aceitas 114 produções científicas divididas em 10 eixos temáticos para as sessões de apresentações de trabalhos. Os eixos estavam constituídos pelas seguintes temáticas: Produção, gestão e uso: que fazer (do) (com) o território brasileiro; Território, população e novas formas de produção; O método da Geografia: uma ontologia do espaço?; Globalização: efeitos perversos; Repensando os lugares: como situação e como relação; Mudanças ambientais globais; Epistemologia da Geografia 
Física; Geografia e construção da cidadania - ensino e pesquisa; Geografia, análise e instrumental técnico; Território e Informação: todas as guerras (MACHADO, 2011).

De acordo com a comissão organizadora do encontro, as contribuições dos discentes, em trabalhos apresentados, demostra a melhoria do nível da pós-graduação brasileira (ENANPEGE, 1995).

O II ENANPEGE realizou-se no Rio de Janeiro - RJ, em 1997, voltado para "Desafios e Alternativas para a Gestão do território". Segundo a organização do encontro, o objetivo central estava em "refletir sobre o saber da Geografia e a prática dos geógrafos diante do atual contexto brasileiro, onde o território é, ao mesmo tempo, expressão da crise do seu autoritarismo nacional e testemunha da busca de novas formas de expressão para sua gestão sustentável” (ENANPEGE, 1997, p.13).

De acordo com Claudio Antonio Gonçalves Egler (em entrevista), a escolha da temática foi retirada no encontro de coordenadores, mas em grande parte foi recomendada por Bertha H. Becker. Complementa que "era um momento complicado, pois estávamos vivendo a desestabilização da economia, um momento de transição [...] tínhamos acabado de lançar o livro (Brasil: uma nova potência regional na economia-mundo), então, tinha um pouco daquela discussão de pensar sobre Brasil" (Entrevista Claudio Antonio Gonçalves Egler, 2016).

Em relação as pesquisas de pós-graduação em Geografia e ao cenário político/econômico/social naquele momento, Claudio Antonio Gonçalves Egler (em entrevista) explica que se faziam pesquisas muito localizadas e pouco sobre o que se estava passando no Brasil, as questões centrais. Desta maneira, lembra que se procurou:

[...] discutir o Brasil, então o foco foi esse, o momento crítico do Brasil, onde explode a inflação, tinha o começo o plano real mas a inflação estava muito alta ...esse momento de transição pegou a gente (Entrevista Claudio Antonio Gonçalves Egler, 2016).

O Encontro teve cerca de 93 resumos publicados, sendo 46 textos das mesasredondas e o restante (47) textos de comunicações livres (MACHADO, 2011).

Os eixos foram divididos em 5 temáticas: $\mathrm{O}$ ensino e a pesquisa em Geografia na Pós-Graduação; Epistemologia e história do pensamento geográfico; Geoprocessamento e cartografia digital; Geografia, gestão do território e meio ambiente; Integração econômica e os novos recortes do território. Estas propostas de trabalhos demonstram um 
quadro dos desdobramentos conceituais, empíricos e as direções tomadas pelos pesquisadores pelo país (ENANPEGE, 1997).

O III ENANPEGE realizou-se em São Paulo - SP, em 1999, ao contrário dos encontros anteriores, constituiu-se por ações e reuniões locais. Gerardi (2003, p. 15) afirma em resposta aos grandes problemas burocráticas enfrentados nessa diretoria, ao contrário do que se vinha realizando até o momento em grandes encontros científicos, foi uma organização de "reuniões de trabalhos com coordenadores e delegados dos programas representantes da área e membros da comissão de avaliação do curso da CAPES, tanto para discutir a pós-graduação, quanto a própria Associação". Naquele momento a diretoria estabeleceu diretrizes e um plano de ação para a entidade.

Como resultado de algumas questões administrativas, esse encontro constitui-se inteiramente de ações dentro da $3^{\text {a }}$ assembleia deliberativa, visando-se, entre as atividades, a modificação do estatuto da entidade; discussão do comitê de avaliação e designação de representantes daquele órgão coordenador e de fomento; sugestões para a Comissão de avaliação de pós-graduação em geografia da CAPES (ENANPEGE, 2009).

O IV ENANPEGE também foi realizado em São Paulo - SP, em 2002, com a temática de "A Geografia no século XXI". O encontro estruturou-se por conferências; mesas redondas; homenagens e sessões de comunicações livres ${ }^{4}$. Sobre a temática geral ${ }^{5}$ do encontro, conforme explica Ariovaldo Umbelino de Oliveira (em entrevista):

[...] a ideia era possibilitar o debate voltado para a Geografia que se estava fazendo por conta de uma virada de século [...] então foi essa a ideia. Nasceu numa conversa com a diretoria. Nós na USP viemos numa tradição de fazer Geografia que não se encanta pelas palavras novas, nos cuidamos de não amarrar temáticas de eventos quaisquer que eles sejam que aconteceram lá, por exemplo, escala não sei o que.... a escala é um problema para os que vão para a cartografia não é um problema para a Geografia como um todo; nós não partimos dessa visão de Geografia. Por exemplo, a escala é uma coisa importante para toda a Geografia? Ela é uma coisa que existe na Geografia e a Geografia se utiliza, mas ela não é um consenso de que é um instrumento. Por isso esse tema super geral de abertura de debate e discussões, que cada campo específico da pós-graduação pudesse se expor, e é evidente que sempre nas mesas redondas têm um temário mais orientado, porque evidentemente era do interesse, e nós procuramos garantir que esse temário e essas mesas redondas tratassem da produção efetiva, e sempre o que interessa as correntes de pensamento e não os grupos de pesquisa, ou mesmo ao curso A, B ou C. Então, nossas mesas sempre foram organizadas pensando que tem que ter alguém, se possível, do positivismo clássico, vamos convidar, se tiver alguém do historicismo, vamos convidar, do empirismo lógico vamos convidar, da fenomenologia vamos convidar, dentro do campo marxista, os idealistas e os materialistas. Então a ideia sempre foi essa, fazer um evento plural (Entrevista Ariovaldo Umbelino de Oliveira, 2015). 
Segundo Ariovaldo Umbelino de Oliveira (em entrevista) o objetivo da diretoria da ANPEGE naquele momento foi garantir que a entidade continuasse tendo uma participação democrática, plural do ponto de vista teórico e do ponto de vista da escolha metodológica.

O V ENANPEGE realizou-se em Florianópolis/SC, em 2003, e tinha como tema norteador "Gestão do território e do ambiente no Brasil: Desafios à formação e à pesquisa em geografia no ensino superior", propiciando aos participantes um maior contato com a produção científica vigente, organização e política de pós-graduação em Geografia no país, bem como, na possibilidade de refletir sobre as transformações presentes no território em várias escalas.

O encontro reuniu 364 produções científicas, estruturados em torno de 5 grandes eixos temáticos: Dinâmica e Gestão do Território; Geografia e meio- ambiente; Região e análise regional; Outros ${ }^{6}$. De acordo com a diretoria daquele biênio, essa delimitação especifica dos eixos temáticos, não diminui as possibilidades da abordagem geográfica, "é certo, apenas possibilitam aglutinar as reflexões em torno de discussões comuns visando identificar avanços na produção científica da geografia brasileira" (ENANPEGE, 2003, p. 2).

O VI ENANPEGE ${ }^{7}$ realizou-se em Fortaleza - CE, em 2005, e apresentou como principal objetivo “cotejar a situação da pós-graduação na perspectiva de se propor ações capazes de estabelecer maior intercambio e cooperação entre programas" (SILVA, 2006, p.282).

O encontro contou com 1 conferência; 8 mesas redondas; 4 mesas/debates; 54 comunicações coordenadas; e 408 produções científicas, assim, reunindo em participação cerca de 567 pessoas (ANPEGE, 2015) . $^{8}$

Nesta edição do ENANPEGE foram organizados 8 eixos temáticos: Local, Regional e Global: redes e dinâmicas territoriais; Cultura, Turismo e Identidade; Os Sistemas naturais; a problemática ambiental; O ensino de Geografia: desafios e práticas; Tratamento e representação da informação geográfica; Urbanização, crise urbana e a cidade no século XXI; Reestruturação produtiva do campo. Como se percebe, há uma ampliação em espaços destinados as sessões temáticas, quando comparado ao encontro antecedente, contemplando novas discussões e campos da Geografia.

O VII ENANPEGE ${ }^{9}$ realizou-se em Niterói/RJ, na Universidade Federal Fluminense, em 2007, tendo como tema norteador "Espacialidade Contemporânea: o Brasil, a América Latina e o Mundo", cumprindo seu papel de apresentar uma discussão 
conceitual e empírica, teórico e prática as rápidas mudanças, configurações e organizações que transcendem a sociedade contemporânea e os importantes condicionantes espaciais.

Segundo entrevista com Márcio Piñon de Oliveira sobre a temática geral do ENANPEGE de 2007, quando o mesmo estava como presidente da ANPEGE, este afirmou que a proposta era a de dar uma dimensão do envolvimento de produção e pesquisa na escala do Brasil, América Latina e Mundo.

Foram publicadas 696 produções científicas, comunicações coordenadas e cientificas, 3 conferências realizadas pelo Edward William Soja, Rogério Haesbaert e Jacques Lévy, bem como cerca de 1033 inscritos, dos quais 52\% eram alunos de pósgraduação (gráfico 2$)^{10}$.

Gráfico 2: Categorias de Inscritos no VII ENANPEGE/2007

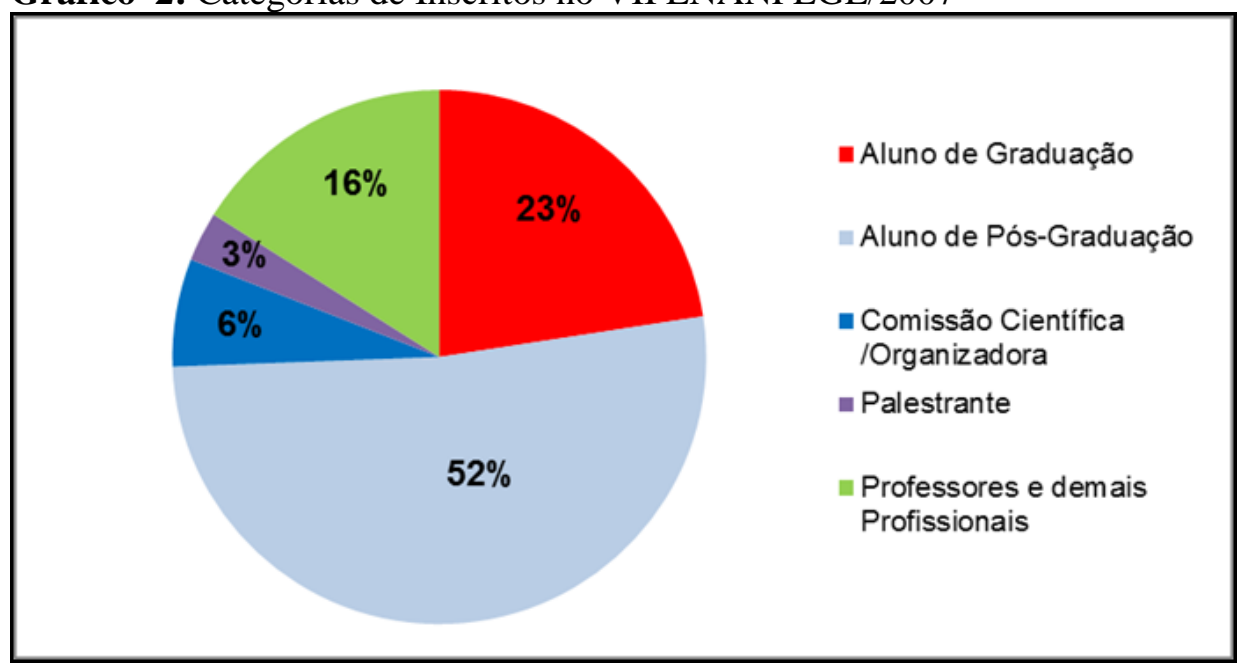

Fonte: Relatório de trabalhos VII Encontro Nacional da ANPEGE.

Org.: TEIXEIRA, V. (2015).

No VII Encontro foram introduzidos os grupos de trabalhos ${ }^{11}$, com uma programação de 19 eixos temáticos: Ensino de Geografia; Epistemologia da Geografia; Espaço e Cultura; Espaço e Movimentos Sociais; Geografia Agrária; Geografia Costeira e Marinha; Geografia Histórica; Geografia Política; Geografia da Saúde; Geografia do Trabalho; Geografia do Turismo; Geografia e Mudanças Climáticas; Geografia e sistema Fluviais; Geoprocessamento e Análise Geográfica; História do pensamento Geográfica; Mudanças no sistema de paisagens; Ordenamento Urbano e Gestão territorial; Regionalização e Globalização; Urbanização da sociedade.

De acordo com Márcio Piñon de Oliveira (em entrevista), é importante destacar que essa ampliação em número de eixos temáticos está atrelada a transformação da 
própria Geografia em seu diverso universo temário e das modificações e fenômenos presentes na organização da sociedade.

O VIII ENANPEGE realizou-se em Curitiba - PR, em 2009, sob a temática "Espaço e Tempo: complexidades e desafios do pensar e do fazer geográfico". Mendonça (em entrevista) ressalta que à ideia sintetiza uma temática provocativa, resultante das reuniões dos programas de pós-graduação do Paraná12, para avançar no campo teórico, analítico e metodológico da Geografia.

Desse modo, a proposta da temática foi sugestiva a vinculação de longa data na Geografia com a epistemologia e de alguns resultados de pesquisas sobre a produção da pós-graduação brasileira de teses e dissertações, que demostrava que as pesquisas na pósgraduação centravam-se em análises muito particularizadas, resultantes, em alguns casos, de uma demanda social de intervenção para o planejamento, da intervenção ambiental etc. Assim, o que se fez foi articular um evento que desse vazam a dimensão do pensar, por isso, espaço e tempo (Entrevista Francisco de Assis Mendonça, 2015).

A discussão proposta no evento aproxima-se ao contexto que passava a Geografia brasileira, que não deixou de elaborar/reconstruir teorias, uma vez que as práticas dos geógrafos, além de suscitar o avanço das concepções empregadas, conduzem a novas matrizes (ENANPEGE, 2009). Dessa forma, é necessário reconhecer que as "motivações para o desenvolvimento de um enfoque que acorda maior atenção a uma Geografia de perspectiva aplicada (fazer) que teórica (pensar) são certamente muitas e de diferentes matizes, e respondem a interesses diversos [...]", conduzindo a muitos questionamentos sobre o desenvolvimento mais amplo de uma em relação a outra (ENANPEGE, 2009).

Entre alguns dos debates pontuados para aquele evento, segundo Mendonça (em entrevista), tinha-se a necessidade de mudanças ao quantitativismo (sentido da produtividade), localismo e empiria simples.

O encontro contou com $634^{13}$ inscritos, sendo que destes $76 \%$ eram estudantes de Programas de pós-graduação associados, $16 \%$ professores de Programas de pósgraduação associados, $4 \%$ estudantes de Programas de pós-graduação não associados, $3 \%$ estudantes de graduação e $1 \%$ demais profissionais (gráfico 3). 


\section{Gráfico 3: Categorias de inscritos no VIII ENANPEGE/2009}

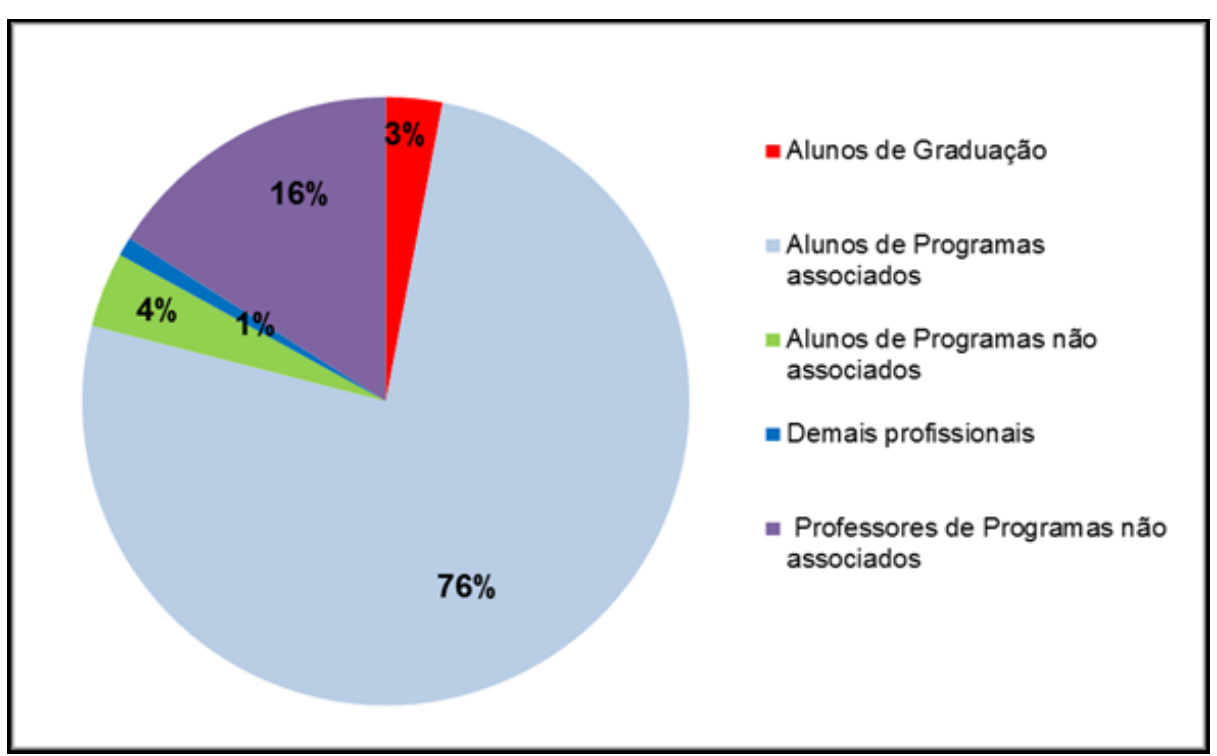

Fonte: Ata da Assembleia deliberativa da ANPEGE, 2009.

Org.: TEIXEIRA, V. (2015).

Nesse encontro foram expostos 613 produções científicas, organizadas 14 mesas redondas com importantes pesquisadores, além de 22 eixos temáticos para trabalhos: Ensino da Geografia; Epistemologia e História do Pensamento Geográfico; Espaço e Cultura; Espaço e Movimentos Sociais; Geografia Agrária; Geografia e Mudanças Globais; Geografia da Saúde; Geografia do Trabalho; Geografia do Turismo; Geografia Histórica; Geografia Política; Dinâmica de Ambientes Fluviais; Geoprocessamento e Análise Geográfica; Processos, Padrões e Mudanças no Sistema de Paisagens; Ordenamento Urbano e Gestão Territorial; Regionalização e Globalização; Urbanização da Sociedade; Espacialidades da Economia; Problemática Socioambiental Urbana; Geografia do Espaço Litorâneo e Marinho; Estado, Território e Fronteira; Geografia das Redes e Mobilidade Populacional (ENANPEGE, 2009).

O IX ENANPEGE realizou-se em Goiânia-GO, em 2011, sob a temática “A pesquisa e a produção geográficas: o pulsar no tempo e no espaço", apresentando uma discussão do pensar e do fazer geográfico, do conhecimento geográfico na compreensão e interpretação do espaço. De acordo com Maria Geralda de Almeida (em entrevista), a diretoria foi responsável por pensar, elaborar e criar a temática, escolhendo o pulsar da Geografia no tempo e no espaço.

Nesse encontro foram organizadas 9 mesas redondas, conferências, fóruns, sessão de pôsteres, homenagens, lançamento de livros, etc. 
O encontro apresentou um total de 856 produções científicas divididas em 30 eixos temáticos de trabalhos - A geografia histórica do espaço; A produção do espaço urbano: perspectiva crítica; A urbanização nos cerrados - processo, formas e vulnerabilidades do urbano atual; Cidade e região; Cidade, imagem e patrimônio; Ensino de Geografia; Espaço, cultura e diferença: as dimensões étnico- racial, ambiental e de gênero e suas ressignificações espaciais; Espaço e cultura: sustentabilidade cultural, paisagens culturais e espaços festivos; espaço e representação; Estado, território e fronteira; Filosofia e epistemologia da Geografia; Geografia agrária; Geografia do crime e da violência; Geografia da saúde; Geografia do espaço costeiro e oceânico; Geografia do trabalho e as contradições do mundo contemporâneo; geografia econômica e social; Geografia e dinâmica territorial do desenvolvimento na Amazônia no século XXI; Geografia, gênero e sexualidade; Geografia e literatura: interlocuções possíveis; Globalização e regionalização; Geomorfologia; Geoprocessamento e análise geográfica; Políticas de renovação das materialidades do território brasileiro: desdobramento e perspectivas; Problemáticas socioambiental urbana; Região, regionalização e políticas territoriais: escala, experiência, atores; Repercussões espaciais das mudanças climáticas Globais; Solos e Geomorfologia em meio tropical; território, turismo e inclusão social; turismo e produção do espaço (ENANPEGE, 2011).

O X ENANPEGE realizou-se em Campinas - SP, em 2013, trazendo como abordagem geral "Geografias, políticas públicas e dinâmicas territoriais", dentro da proposta de dois grandes eixos de reflexões responsáveis pela interpretação e pelas ações sobre as dinâmicas territoriais, assim, a Geografia e sua crescente produção e estruturação institucional de pesquisa, no Brasil, e o seu papel na orientação social, econômica, política, cultural tecnológica e ambiental das políticas públicas no país vinculadas as dinâmicas territoriais.

Em entrevista Maria Tereza Duarte Paes, presidente da diretoria da ANPEGE naquela ocasião, esclarece a constituição da temática geral do encontro, informando que a questão das políticas públicas era temática vertical das mesas redondas no sentido de relacionar a produção científica com a prática, o exercício mesmo das politicas públicas. Lembra, ainda, que foram grandes os esforços para abrir espaço no ENANPEGE para representantes dos órgãos públicos no sentido de fortalecer o diálogo, de tornar a ANPEGE mais representativa em termos de seu reconhecimento público e das políticas públicas - com mais veemência e reivindicando postos de trabalhos, uma vez que, a Geografia pensa o território, pensa a produção, pensa a área e outros. 
O encontro contou com 1.455 inscritos, sendo $67,7 \%$ pagantes e $4,81 \%$ ouvintes, conforme gráfico $4^{14}$.

Gráfico 4: Categorias de inscritos no X ENANPEGE/2013

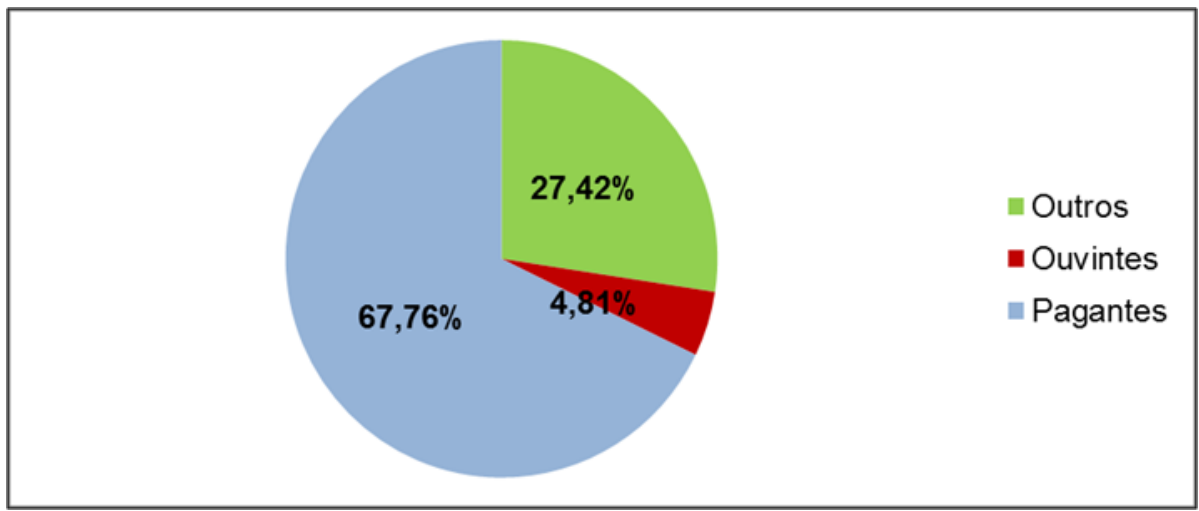

Fonte: Site ANPEGE- Histórico.

Org.: TEIXEIRA, V. (2016).

*não foi encontrado demais informações a categoria Outros.

Nesse encontro a conferência de abertura foi realizada por Christian Topalov, com mesas redondas; fóruns de coordenadores, fóruns pesquisadores, fóruns editores e fóruns estudantes; lançamento de livros; sessões de pôsteres; entregas de melhor tese e dissertação. Nessa edição fizeram-se homenagens aos ex-presidentes das gestões anteriores (dois em homenagens póstumas - Milton Santos e Bertha Koifmann Becker, e os professores Lucia Helena Gerardi, Ariovaldo Umbelino de Oliveira, Gerusa Maria Duarte, José Borzachiello da Silva, Márcio Piñon de Oliveira, Francisco de Assis Mendonça e Maria Geralda de Almeida.

O encontro reuniu um total de 903 produções científicas, expostas em 31 eixos temáticos, sendo que foram mantidos alguns eixos do encontro anterior e incluídas novas propostas, tais como: Geografia e políticas públicas ${ }^{15}$; Movimentos sociais e reforma agrária; Dinâmica da paisagem, recursos naturais e planejamento ambiental; Geografia agrária e sustentabilidade; Espaço e circulação: transportes, telecomunicações e logística; Territorialidades de festas populares: espaço-tempo cognitivo, conectivo e conflito.

Segundo Saquet (2011, p. 12) "a produção do conhecimento - pensamento é processual e relacional, ao mesmo tempo, resultado e condições da relação de unidade espaço - tempo. Vivemos a unidade espaço-tempo todos os dias, a cada minuto, a cada segundo, em qualquer lugar e território". Dentro dessa perspectiva, percebe-se que as temáticas dos grupos de trabalhos dos ENANPEGE são reflexo dessa transformação e complexificação dos estudos geográficos retratados da realidade. 
É por isso, de acordo com Vitte (2009, p. 91), que nas "últimas décadas estamos assistindo um debate relativo aos avanços da Geografia e de suas subdisciplinas", inclusive na representatividade do ENANPEGE para a contribuição da produção científica, o que tem permitido a constatação da pluralidade da Geografia, os temas emergentes e aqueles fragilizados (Entrevista Maria Geralda de Almeida, 2016).

Ao fazermos um paralelo em relação as atribuições dos eixo temático, Geografia é uma questão complexa, uma vez que as sessões temáticas dos grupos de trabalhos (GTs) são propostas pela comunidade acadêmica de diversas programas de pós-graduação em Geografia do país ${ }^{16}$, e quando enviadas precisam ser aprovadas pelo comitê da organização do evento. Desta maneira, a apreensão do conjunto de eixos temáticos dos grupos de trabalhos requer a incorporação de muitas outras variáveis.

O quadro 1 sistematiza a cronologia das edições do ENANPEGE, bem como o local de ocorrência dos eventos e suas respectivas temáticas gerais.

Quadro 1: Cronologia de realização do ENANPEGE (1995-2015)

\begin{tabular}{|c|c|c|c|}
\hline ENANPEGE & Ano & Temáticas dos eventos & Cidade / Estado \\
\hline I & 1995 & Território Brasileiro e Globalização & Aracaju - SE \\
\hline II & 1997 & $\begin{array}{c}\text { Desafios e Alternativas para a Gestão do } \\
\text { Território }\end{array}$ & Rio de Janeiro- RJ \\
\hline III & 1999 & & São Paulo - SP \\
\hline IV & 2002 & A Geografia no Século XXI & São Paulo - SP \\
\hline V & 2003 & $\begin{array}{c}\text { Gestão do território no Brasil: Desafios a } \\
\text { formação e a pesquisa em geografia no } \\
\text { ensino superior }\end{array}$ & Florianópolis - SC \\
\hline VI & 2005 & - & Fortaleza - CE \\
\hline VII & 2007 & $\begin{array}{c}\text { Espacialidade Contemporânea: o Brasil, } \\
\text { a América Latina e o Mundo }\end{array}$ & Niterói - RJ \\
\hline VIII & 2009 & $\begin{array}{c}\text { Espaço e Tempo: complexidades e } \\
\text { desafios do pensar e do fazer geográfico }\end{array}$ & Curitiba - PR \\
\hline IX & 2011 & $\begin{array}{c}\text { A pesquisa e a produção geográficas: o } \\
\text { pulsar no tempo e no espaço }\end{array}$ & Goiânia - GO \\
\hline$X$ & 2013 & $\begin{array}{l}\text { Geografias, políticas públicas e } \\
\text { dinâmicas territoriais }\end{array}$ & Campinas - SP \\
\hline $\mathrm{XI}^{*}$ & 2015 & $\begin{array}{l}\text { A diversidade da geografia brasileira: } \\
\text { escalas e dimensões da análise e da ação. }\end{array}$ & $\begin{array}{c}\text { Presidente Prudente } \\
\text { - SP }\end{array}$ \\
\hline
\end{tabular}

Fonte: Anais da ANPEGE.

Org.: TEIXEIRA, V. (Maio/2015).

(-) dados não encontrados.

*Em um balanço prévio feito ao final da plenária de encerramento, o encontro, apresentou-se 973 participantes, sendo 145 coordenadores dos 41 GTs e totalizou 989 trabalhos aprovados. 
Pelos dados do quadro 1 foi possível fazer um apanhado geral sobre as abordagens temáticas do ENANPEGE. A questão territorial, está presente nas discussões desde a primeira realização do evento, no ano de 1995, um reflexo, por ter desde as últimas décadas do século XX, geógrafos brasileiros se "dedicado a elucidar, com maior ênfase, a complexidade das sociedades contemporâneas por meio do território, de suas relações com o espaço e o tempo" (SILVA, 2010, p. 241). Momento político aquele, que se "decretava o fim da história e da bipolaridade entre socialismo e capitalismo, o advento da era da globalização e o fim dos estados nacionais territoriais [...]" (SILVA, 2010, p. 223) e outros.

Há uma preocupação, ainda, com as variáveis espaço e tempo e a problematização das pesquisas em Geografia e sua agenda temática, por meio da menção a formação e a pesquisa e ao fazer geográfico a partir dos propósitos de transformação e de organização espacial que os cenários nacional e internacional apresentam.

Nessa perspectiva, os desafios postos pelo mundo contemporâneo e as mudanças mais rápidas da realidade fizeram parte dos eventos, podendo-se resumir em quatro questões temáticas gerais: território, espaço, temporalidade e escalaridade.

Assim, no desenhar dos novos temas de investigação, os encontros da ANPEGE procuram oferecer condições para que os geógrafos de nível de pós-graduação em Geografia possam expor suas visões de mundo, suas concepções teóricas e metodológicas e suas práticas para a produção do conhecimento geográfico sobre os fenômenos recorrentes na sociedade e sua relação com a natureza.

Por fim, pode-se afirmar que os trabalhos publicados nos Anais do ENANPEGE são representantes dessas várias leituras dos diferentes espaços-tempo, legado científico deixado pelos geógrafos como contribuição a um dado momento histórico, entendido como uma amostragem das temáticas priorizadas em estudos no Brasil.

A partir dos dados e informações apresentados, buscou-se entender o tratamento dado a alguns temas científicos, seja por maior ênfase, por limitações ou por renúncia de abordagens. Este fato demonstra, assim, "escolhas constituídas pelo entrelaçamento de razões de natureza epistemológica, política, ideológica e institucional, que condicionam a produção científica" (FERNANDES, 2003, p.1) em diferentes áreas e subáreas dentro de uma mesma ciência, neste caso a Geografia. 


\section{Notas}

1 - As reflexões apresentadas no referente texto, são parte estruturadora do capítulo "ANPEGE e ENANPEGE: a produção geográfica brasileira, da Dissertação do programa de pós-graduação em Geografia da UNICENTRO-PR.

2 - As edições de 1997 (II ENANPEGE), 2002 (IV ENANPEGE), 2003 (V ENANPEGE) e 2011 (IX ENANPEGE) não contam o número de participantes correspondente as suas edições.

3 - Na assembleia final de 1995, entre as atribuições estabelecidas estava a aprovação de uma moção na qual se alertava para o problema que atravessa a Universidade Pública Brasileira, particularmente as Universidades Federais, encaminhada junto ao Conselho de Reitores das Universidades Brasileiras (CRUB) a qual conduziria ao Presidente da República, Ministros de Estado, membros do Congresso Nacional, etc, sob a defesa Universidade e o ensino público e gratuito.

4 - Não foi localizado material que pudesse subsidiar outras informações sobre esse evento.

5 - Vale salientar que as temáticas gerais que compõem os eventos são indicações de propostas a quais devem ser aprovadas nos Fórum dos coordenadores de programas de Pós-graduação.

6 - O quinto eixo temático estava intitulado como "outros"; onde se percebe trabalhos da Geografia Física como Geografia Humana com abordagens para a questão política, turismo, geomorfologia, urbana; etc.

7 - Esse material foi disponibilizado pelo professor José Borzacchiello da Silva. Acesso em 12 de maio de 2015.

8 - Informações obtidas no site da ANPEGE. Disponível em < http://www.anpege.org.br/?op=6> Acesso em 24 de maio de 2015.

9 - Material encontra-se disponível no site da ANPEGE (www.anpege.org.br). Acesso em 13 de fevereiro de 2015.

10 - Segundo dados do relatório do evento: Palestrante (31); Comissão cientifica/organizadora (68); professores e demais profissionais (166); aluno de graduação (233); aluno de pós-graduação (535).

11 - Informações fornecidas por Márcio Piñon de Oliveira (em entrevista).

12 - Para a organização do VIII encontro, em 2009, foi realizado um evento colegiado com os cinco programas de Pós-graduação do Paraná para a criação de uma macro comissão do ENANPEGE, a qual deliberava questões do evento (as pautas, quem convidar, como organizar). Desta forma, foram 13 pessoas, ou seja, a Diretoria da associação e os Coordenadores e representantes de cada Programa de Pós-Graduação em Geografia do estado do Paraná. Assim, foi uma construção da Diretoria da ANPEGE com o Paraná, bem como, a diretoria tomou o cuidado e a preocupação de enviar para todos os programas de pós-graduação do país questões para discussão (e devolução à diretoria) sobre vários aspectos do encontro, onde a maior parte respondeu de forma positiva e sugerindo temas e ampliação de temas que não estavam contempladas inicialmente. (Entrevista Francisco Mendonça, 2015).

13 - Em números absolutos foram 6 inscritos como "Demais profissionais"; 19 inscritos como Alunos de Graduação; 25 inscritos como Alunos de Programas não associados; 101 inscritos como Alunos de Programas não associados; e 482 Alunos de Programas associados.

14 - Assim, 986 pagantes, 70 ouvintes e 399 outros. Vale salientar que categoria "outros" foi atribuída por nós, tendo em vista que pelos dados informados chegava-se apenas a um total de 1.056 participantes, faltando-se 399 participantes, o que poderiam estar em outras formas de participação no ENANPEGE. 
15 - Segundo Fernandes (2015, p. 144) de acordo com o relatório do balanço sobre as participações do Grupo de Trabalho Geografia e Políticas Públicas, e percebe-se que "havia uma grande diversidade de políticas analisadas em diferentes escalas e recortes temporais; como os trabalhos apresentados focavam em uma política ou experiências, ocorria uma fragmentação das políticas públicas; as análises sobre a etapa de avaliação predominava sobre as demais etapas (criação da agenda, formulação e implementação); "leituras do Estado" divergentes; a abordagem de assuntos relevantes como papel dos agentes, conflitos de interesses, relação público x privado e o conceito de políticas públicas era realizado de forma superficial; e por fim, havia pouco rigor com o debate geográfico".

16 - No último ENANPEGE (UNESP Presidente Prudente/2015), para a definição dos Gts, as propostas deveriam ser cadastradas e analisadas, devendo seguir alguns critérios, tais como: os coordenadores deveriam estar filiados a programas adimplentes com a ANPEGE; cada GT deveria ter quatro coordenadores (sendo no mínimo de dois estados e três programas diferentes) e dois suplentes; Os coordenadores não poderiam ter trabalhos inscritos nos seus GTs. Assim, percebe-se que essa forma de organização dos Gts objetivou garantir a pluralidade dos diferentes grupos de pesquisa e dos diferentes programas desses Gts, bem como, estabelecer uma rede interristitucional, isso é, uma forma de subsidiar o fortalecimento de redes de pesquisa em Geografia no país. De acordo com Borzachiello (em entrevista), é uma ideia de uma rede a partir de uma afinidade de pesquisa e afinidade temática, uma rede não institucionalizada, mas uma rede de várias perspectivas da Geografia Agrária, da Geografia urbana, geomorfologia, climatologia, do ensino, das questões ambientais e outras.

\section{Referências}

ANAIS. I Encontro Nacional da Associação Nacional de Pós-Graduação e Pesquisa em Geografia, 1. Aracaju, 1995.

ANAIS. II Encontro Nacional da Associação Nacional de Pós-Graduação e Pesquisa em Geografia, 2. Rio de Janeiro, 1997.

ANAIS. V Encontro Nacional da Associação Nacional de Pós-Graduação e Pesquisa em Geografia, 5. Florianópolis, 2003.

ANAIS. VI Encontro Nacional da Associação Nacional de Pós-Graduação e Pesquisa em Geografia, 6. Fortaleza, 2005.

ANAIS. VII Encontro Nacional da Associação Nacional de Pós-Graduação e Pesquisa em Geografia, 7. Niterói, 2007

ANAIS. VIII Encontro Nacional da Associação Nacional de Pós-Graduação e Pesquisa em Geografia, 8. Curitiba, 2009.

ANAIS. IX Encontro Nacional da Associação Nacional de Pós-Graduação e Pesquisa em Geografia, 9. Goiânia, 2011.

ANAIS. X Encontro Nacional da Associação Nacional de Pós-Graduação e Pesquisa em Geografia, 10. Campinas, 2013.

BOLETIM INFORMATIVO DA ANPEGE. Associação Nacional de Pós-Graduação e pesquisa em Geografia. Boletim. [s.i], n. 4, 2. Quinz., Agos., 2007.

BOLETIM INFORMATIVO DA ANPEGE. . Associação Nacional de Pós-Graduação e pesquisa em Geografia. Boletim. [s.i], n. 08 , Fev., 2009.

Estatuto da Associação Nacional de Pós-Graduação e Pesquisa em Geografia - ANPEGE. Porto Alegre, 2010. 
$\overline{\text { Encontro Nacional de Pós-graduação em geografia no Brasil. Ata. n.1, Assembléia geral, }}$ São Paulo, 1984.

Encontro Nacional de Pós-graduação em geografia no Brasil. Ata.n.2, Assembléia geral, Rio de Janeiro, 1986.

Encontro Nacional de Pós-graduação em geografia no Brasil. Ata. n.3, Assembléia geral, Rio Claro/SP, 1987.

Encontro Nacional de Pós-graduação em geografia no Brasil. Ata. n.4, Assembléia geral, Santa Catarina, 1993.

Entrevista com a professora Lúcia Helena de Oliveira Gerardi. Geosul, Florianópolis, v. 18, n. 36, p 175-190, 2003

FERNANDES, Suellen Walace Rodrigues. Contribuições da Ciência Geográfica às Políticas Públicas. Tese (Doutorado em Geografia), Universidade de Brasília, 2015.

FERNANDES, N. N.. Geografia Cultural, festa e cultura popular: limites do passado e possibilidades do presente. Espaço e Cultura, Rio de Janeiro: UFRJ, [s.i] n.15, 2003.

GERARDI, L. H. O. O ensino e a pesquisa na pós-graduação em Geografia - velhas questões, novas perspectivas. In Anais II ENCONTRO NACIONAL DA ANPEGE, Rio de Janeiro, 1997.

GERARDI, L.H. O. ANPEGE: O resgate de uma história. Revista da ANPEGE, ano 1, n. 1, Curitiba- PR, 2003.

MACHADO, Valeriê Cardoso. O Tratamento da questão ambiental na Geografia Brasileira: Uma análise dos Anais dos eventos científicos de Geografia e Educação entre 1980 e 2008. In Anais, 9. Encontro Nacional da Associação Nacional de pesquisa e pósgraduação em Geografia, Goiânia-Go, 2011.

SAQUET, M. A. Por uma Geografia das territorialidades e das temporalidades: uma concepção multidimensional voltada para a cooperação e para o desenvolvimento territorial. 1 ed. São Paul: outras expressões, 2011

SILVA, Ana Cristina da. O pensamento geográfico brasileiro na travessia do século XX para o XXI : o território na trama das significações imaginárias. Tese (doutorado em Geografia), Universidade Estadual Paulista, Faculdade de Ciências e Tecnologia, Presidente Prudente, 2010.

VITTE, A. C. Teorias do método cientifico e geografia. Um ensaio a partir da noção de paradigma de Thomas Kuhn. In MENDONÇA, F. A.; LOWEN-SAHR, C. L.; SILVA, M.(Org.). Espaço e Tempo. Complexidade e desafio do pensar e do fazer geográfico. Curitiba: ADEMADAN, 2009. 